\title{
An Investigation of Syntactic Errors in Chinese Undergraduate EFL Learners' Compositions: A Cohort Study
}

\author{
Meihua Liu \\ Department of Foreign Languages and Literatures, Tsinghua University \\ Chengfu Rd., Qinghuayuan, Beijing, 100084, China \\ Tel: 86-10-62772459 E-mail: ellenlmh@yahoo.com \\ Ying Xu \\ Department of English and International Studies, China Foreign Affairs University \\ 24 Zhanlan Rd., Xicheng District, Beijing, 100037, China \\ E-mail: xuying@cfau.edu.cn
}

Received: 15-03-2013

Accepted: 23-05-2013

Published: 01-07-2013

doi:10.7575/aiac.ijalel.v.2n.4p.182

URL: http://dx.doi.org/10.7575/aiac.ijalel.v.2n.4p.182

\begin{abstract}
This paper reports on a study of syntactic errors in English essays composed by Chinese university students. Thirty undergraduate non-English majors across disciplines produced 90 essays on three tasks during eight weeks, and answered a self-developed questionnaire at the end of the course. Analyses of the data resulted in the following main findings: (1) Among the ten types of syntactic errors, errors in tense and voice were the most frequently occurring type of errors, (2) the errors generally tended to decrease across tasks, (3) the syntactic errors of various categories were generally inversely correlated with the students' writing performance, and (4) the errors were caused by diverse reasons, of which carelessness and the differences between Chinese and English were considered the most crucial.
\end{abstract}

Keywords: syntactic error; writing performance

\section{Introduction}

With China's increasing economic and cultural interaction with the rest of the world, the ability to use English proficiently in the written and/or oral form proves to be a necessary skill to find or hold a job for most Chinese university graduates and other people who desire to survive an international working environment. For years, English writing has been a nutshell to EFL learners, teachers and researchers because, despite the increasing need to write well in English, quite a number of Chinese university students cannot write effectively in English (Liu \& Braine, 2005; Wang, 2005).

In order to understand how well Chinese EFL learners write in English, much research has been done in the area, some focusing on the composing process, including the influence of Chinese on English writing, writing strategies, text pattern knowledge, task difficulty, and writing anxiety (Cai, 2001; Wang, 2003; Wang, 2005). Some research is concerned with written texts, such as error analysis, sentence variety, cohesive devices, syntactic and lexical features, and rhetorical devices (Du, 2004; Liu \& Braine, 2005; Su, 2002; Tang, 2000). Some studies investigate the assessment of English writing, such as raters' bias, error treatment, and the rating process (Liu \& Chai, 2009; Zhang, 2004). Thanks to these efforts, many problems existing in the English writing of Chinese EFL learners have been revealed and great improvement has been gained so far. Even so, the quality of the learning outcome is still far from satisfying for both students and teachers. As a result, it is still necessary to continue research on various aspects of English writing. The present research sought to investigate the syntactic errors in 90 English essays composed by 30 Chinese undergraduate non-English majors on three tasks over a period of 8 weeks. Meanwhile, the study examined the patterns of the syntactic errors across the three tasks, the relationship between different types of syntactic errors and the students' writing performance, and the causes for the errors.

\section{Literature review}

Errors are generally regarded as linguistic deviations (Corder, 1967; Bardovi-Harlig \& Bofman, 1989; James, 1998; Taylor, 1986). Sometimes a researcher may venture to adopt a much broader definition of errors to fit a specific research purpose. For example, Zhang and her colleagues (1995) examined both linguistic/grammatical and rhetoric/discourse errors in their study.

Since 1970s, research on written errors has been flourishing. While pure error analysis (EA) continues to be an issue of interest, focus gradually shifts from a comprehensive analysis of written errors to a more sophisticated analysis of specific types of errors.

A common feature of pure EA studies is to go to great lengths to categorize errors and calculate the proportion/percentage of certain type of errors of the total number of errors, thus uncovering its correlation with 
learners' writing performance (Cheng, 1994; Frantzen, 1995; Hyland \& Anan, 2006; Khuwaileh \& Shoumali, 2000; Kim, 2001; Tang, 2000). Khuwaileh and Shoumali (2000), for example, examined the sentential errors in academic English writing produced by 93 senior Arab English learners, and reported a high percentage of lexical errors. Kim's (2001) comprehensive error analysis of 60 summary writing produced by Korean university EFL learners revealed that syntactic errors were the most serious, followed closely by lexical errors. However, these two studies were discrepant in defining lexical errors, with the former categorizing some morphological errors as lexical errors while the latter recognizing them as syntactic errors. In Cheng's (1994) study, six first-year English majors and three second-year English majors from a Chinese university in Beijing produced 455 errors in their English essays. With the help of two native English speakers, the researcher identified four categories of errors: morphological, lexical, syntactic, and semantic errors, with several subcategories in each type. The study found that syntactic errors were the most damaging, followed by semantic and morphological errors. Nevertheless, the study did not present any scheme of how to categorize the errors. Instead of explaining what semantic errors were, the study just subcategorized them as a type of errors of "deviation from original meaning", "indefiniteness/inexplicitness", "ambiguity" or "irrelevance".

Studies focusing on more specific types of errors in L2 writing have revealed much richer findings (Crompton, 2005; Hsin, 2003; Huang, 2001; Liu \& Yang, 2006; Su, 2002). For instance, Su (2002) analyzed errors of three high frequency verbs (buy, wait and learn) in the interlanguage of Chinese EFL learners based on "the Chinese Learners' English Corpus". The study classified the errors into six categories: omission, addition, misinformation, mis-ordering, false friend and ambiguity. Explaining these errors from an inter-lingual and intra-lingual view, the researcher suggested that Chinese EFL learners should learn to accept the target language details unconditionally and learn to use an English-English dictionary.

In addition to pure EA, more and more studies tend to employ EA as an analytical technique to explore the relationship between errors and other variables (e.g., syntactic transfer, error feedback, cohesion, writing proficiency, etc.) in L2 writing (Chan, 2004; Crusan 2002; Dam, 2001; Feng, Ogata \& Yano, 2000; Ferris \& Roberts, 2001; French, 2005; Hinkel, 2001; Polio, 1997). For example, French (2005) examined the errors in 744 drafts written by 248 college students to determine if there was a level of acceptance of errors due to the influence of L1 (Japanese) and whether the errors were becoming part of an accepted, standardized Japanese English. It was found that there was little acceptance of third person "-s", article and plural errors in student writing, but there was a measured degree of acceptance of the errors with regard to sentence combining and sentence fragments, omission of subject, generalizing or obscuring of subjects, and omission of expected superlatives. Zhang et al. (1995) administered a multiple choice test and an essay writing test to 138 non-English majors and 62 English majors from a Chinese university. The researchers found that the non-English majors did much better in the multiple choice task than in the writing task while the former group did better the other way around, and that the non-English majors produced far more errors in the writing task than the former group did. They also found that rhetorical problems were much worse than grammatical problems in both the two groups' writing.

As such, it is generally revealed that syntactic and lexical errors are the leading problems in EFL learner's writing. Nevertheless, little research has investigated the errors across tasks and/or over a longitudinal period of time. To fill in the gap, the present research analyzed the syntactic errors in 90 English essays written by 30 undergraduate non-English majors from a prestigious Chinese university on three tasks over a period of 8 weeks. Another aim of the present study was to explore whether formal instruction had any effect on the students' writing in terms of syntactic errors. The following research questions were of particular interest:

(1) What syntactic errors are made by the university EFL students in their English writing?

(2) What is the developmental pattern of the syntactic errors across the three writing tasks over a period of eight weeks?

(3) What is the relationship between the syntactic errors and the students' writing performance?

(4) What do the learners generally believe the sources of their errors are?

\section{Research design}

Participants: Thirty out of 40 students of an intermediate-level English Writing course in a prestigious university in Beijing participated in the present study. The course lasted for eight weeks, adopted a mixed method of lecturing, and review and discussion, and focused on four types of writing: free writing, letter writing, review writing and argumentative writing. With an age range from 19 to 21 and an average age of 20.3, the students came from various disciplines and were all second-year non English majors. The students met the teacher once a week, each time lasting 90 minutes.

Instruments: To answer the research questions, the researchers collected all the essays produced by the students and the scores on each essay, and administered a survey as detailed below.

The writing sample: The two English Writing classes were required to finish four writing tasks, namely, free writing (task A), letter writing (task B), review writing (task C), and argumentative writing (task D) with an average of 200 words per piece during the eight weeks. Each task had to be completed within two days after it was assigned and was provided detailed feedback both on the sentence and discourse levels the following week. All the 120 essays were collected as potential samples for the present research. Nevertheless, because many fixed expressions or sentence structures were identified in the essays of letter writing, task B was excluded from the present research. This yielded 90 valid samples for the present study. 
The survey: To obtain the students' perceptions on syntactic errors in their writing, the researchers self-developed a 25item questionnaire based on literature review and the researchers' teaching experiences. The questionnaire was then double-checked by two experts in the area and piloted to five second-year undergraduates, which resulted in a 16-item survey (see Appendix). The final survey covered the following three aspects: (1) general perspective on the difficulty of writing grammatically correct English sentences (item 1), (2) views on the syntactic errors they were likely to make in their English writing (items 2-9), and (3) perceptions on possible causes for the errors in their English writing (items 1016). All the survey items were designed on a 5-point Likert scale ranging from 'Strongly disagree' to 'Strongly agree' with values 1-5 assigned to the descriptors respectively. To further examine the students' ideas about the difficulties and causes for the errors in their English writing, two open-ended questions were added to the survey. The participants answered this questionnaire written in both Chinese and English in 10 minutes at the end of the course.

English writing performance: The participants' scores in the three writing tasks were considered as their writing performance in English.

Data analysis: The researchers adopted the scheme of classifying written errors developed by Kramer, Leggett and Mead (1995) for data analysis. During the coding process, the researchers followed the following rules: 1) a repeated error should only be coded once, 2) if one error causes a series of other errors, only the first error is coded, and 3) if the coder is not absolutely sure about the nature of an error, both the writer and a native English teacher should be consulted. Thus, with an inter-coder reliability score (Cronbach alpha) of .876, the researchers identified 1138 errors at sentence, paragraph, and discourse levels in the 90 English compositions, 622 of which were syntactic errors.

The coded errors were then analyzed statistically to explore the overall picture of the errors produced by the participants across the tasks. To reveal the developmental patterns of the errors across the tasks, paired samples t-tests were run. Then, correlational analyses were employed to determine how the errors were correlated with the student's writing performance. At the same time, responses to the open-ended questions were analyzed to identify the students' perceptions on the difficulties and possible causes for making syntactic errors in their English writing. The results were incorporated into the description and discussion of the actual errors found in the English essays.

\section{Results and discussion}

\subsection{General pattern of the syntactic errors}

\subsubsection{General pattern of the syntactic errors of the whole sample}

Of 1138 identified errors at sentence, paragraph and discourse levels in the 90 essays on three tasks, 622 were syntactic errors, accounting for $55 \%$ of the total number of errors, meaning that syntactic errors were the greatest challenge for the students in their English writing. These 622 syntactic errors were grouped into ten categories ( $\mathrm{Sa}-\mathrm{Sj})$, as reported in Table 1, among which errors in tense, voice and modality $(\mathrm{Sb})$ accounted for the largest percentage $(25.1 \%)$, followed by agreement errors $(\mathrm{Sd})(13 \%)$, conjunction errors $(\mathrm{Sc})(12.1 \%)$, and the wrong use of articles $(\mathrm{Si})(11.6 \%)$.

Table 1. Syntactic Errors of the Whole Sample

\begin{tabular}{ll}
\hline Types of syntactic errors & Number and percentage of errors \\
\hline Sa (errors in part of speech) & $56(9 \%)$ \\
\hline Sb (errors in tense, voice \& modality) & $156(25.1 \%)$ \\
\hline Sc (errors in coordinating and subordinating conjunctions) & $75(12.1 \%)$ \\
\hline Sd (errors in agreement) & $81(13 \%)$ \\
\hline Se (run-on, fragment \& dangling participle) & $41(6.6 \%)$ \\
\hline Sf (errors in word order) & $31(5 \%)$ \\
\hline Sg (ill parallelism or ill comparison) & $23(3.7 \%)$ \\
\hline Sh (mixed structure) & $57(9.2 \%)$ \\
\hline Si (errors in the use of articles) & $72(11.6 \%)$ \\
\hline Sj (errors in the use of single or plural forms) & $30(4.8 \%)$ \\
\hline Total & $622(100 \%)$ \\
\hline
\end{tabular}

\subsubsection{Errors in tense, voice, and modality}

Errors in tense, voice, and modality in the present study involved errors concerning predicate verbs (tense, aspect, voice, and mood) and auxiliary verbs or modals. For example:

(1)..., the teaching resource should be redistribute.

(2) However, I am not mean that we should treat animals badly.

In example (1), the supposed passive voice be redistributed was not used correctly, and in example (2), the link verb am was deployed instead of the proper auxiliary verb $d o$.

The survey data revealed a similar pattern: $40 \%$ of the respondents (strongly) endorsed item 2 (I often make mistakes in tense, voice and mood), meaning that the use of tense, voice, mood and modality was a (big) challenge for more than a third of the participants.

\subsubsection{Errors in agreement}


Errors in agreement basically included three subcategories in the present study: errors in subject-predicate agreement, errors in determiner-noun agreement and errors in pronoun-antecedent agreement. This type of errors accounted for $13 \%$ (81) of the total syntactic errors in the present study and can be illustrated by the following examples.

(3) Animal rights activists always insists on abandoning animal use in medical research.

(4) Everyone has our own holiday plan ....

Subject-predicate disagreement occurred in example (3), while pronoun-antecedent disagreement happened in example (4) where everyone and our did not match each other in terms of reference.

As reported in the Appendix, $45 \%$ and $47 \%$ of the participants (strongly) believed that they were able to appropriately use subject-predicate agreement (item 7) and pronoun-antecedent agreement (item 8) respectively. Even so, the result showed that at least one-third of them still had much difficulty in agreement in their English writing. This might be because there is no agreement in their mother tongue, Chinese.

\subsubsection{Errors in coordinating or subordinating conjunctions}

In the present study, errors in coordinating or subordinating conjunctions only included the cases of misusing coordinating or subordination conjunctions, while the lack of necessary conjunctions was considered an error of run-on sentences. The present study identified 75 (12.1\%) errors of this category, being the third most frequently occurring type of syntactic errors. Conformant to this, only $37 \%$ of the participants (strongly) endorsed that they were not good at using conjunctions while $44 \%$ vetoed the statement (item 6), as reported in the Appendix. The following are two examples.

(5) What we should do is that enjoy our lives in a healthy way.

(6) In a word, this book is not only well written and inspires us to think more.

In example (5), the writer failed to write a grammatically complete sentence for the object clause introduced by that. Example (6) should be "..., this book is not only well written but (also) inspires us to think more", but the writer wrongly used the coordinating conjunction and to connect the two clauses.

\subsubsection{Errors in the use of articles}

$72(11.6 \%)$ errors in the use of articles were spotted in the present study, which mainly involved the errors in the use of $a$, an or the, and those resulting from the lack of an article or any other determiners before a noun. For example,

(7) A lecture from $\wedge$ famous writer Yu Hua, ....

(8) This film tell us a interesting story.

\subsubsection{Errors in the use of single or plural forms of nouns}

In the present study, if a single form or a plural form of a noun was misused, or an uncountable noun was misused as a countable noun, it was counted as an error in the use of single or plural forms of nouns. However, if a noun phrase was modified by a determiner, it was first checked whether it was an agreement error; if it was, it was not counted as an error of misuse of single or plural forms of nouns. Eventually, $30(4.8 \%)$ errors of this kind were identified in the present study, which can be shown by the following examples.

(9) Facing his children Christopher, Chris was always trying his best to love and protect him, ....

(10) Here are some advices for freshmen.

As such, most of the students had no difficulty properly using the singular or plural form of a noun in their English writing. This is further supported by their responses to survey item 9, as shown in the Appendix.

To summarize, as reported in the Appendix, although $64 \%$ of the respondents did not believe they had much difficulty in writing grammatically correct sentences (item 1), and most denied that they often made mistakes in tense and voice (item 2), in part of speech (item 4), in complex sentences (item 3), and in the use of articles (item 5), they still had difficulty in writing grammatically correct English sentences to varying degrees. In addition, their answers to the openended question (item 17) showed that 12 of them claimed that they often made mistakes in tense, voice and mood of verbs, the use of articles, use of agreement, and long and complex sentences in their English writing, consistent with the analyses of their real writing products.

\subsubsection{Errors in part of speech}

Errors in part of speech refer to the situations where the part of speech of a word does not match its function in a sentence (Kramer et. al, 1995). For example, the word quick in the sentence I ran very quick is considered an error in part of speech because it is an adjective instead of an adverb. In the present study, 56 (5.4\%) errors of this kind were coded, implying that the students have little difficulty in properly using part of speech. This was actually evidenced by the students' responses to the survey items. As shown in the Appendix, $67 \%$ of the respondents (strongly) disagreed with item 4 (I often make mistakes in part of speech). Of the 56 errors in part of speech, most were about the misuse of an adjective as an adverb, a noun as a verb or an adjective, an adjective as a verb, or the other way around. For example:

(11) ..., but never forget to study! Keep them in well balance.

(12) What we cannot lose is an honesty heart, ...

(13) To make up our disadvantages and develop our economy swifter, ... 
In example (11), an adverb instead of an adjective was used to modify the noun (good balance), and a noun instead of an adjective was used to describe another noun (honest heart) in example (12). In example (13), an adjective rather than an adverb was utilized to modify the verb 'develop'.

\subsubsection{Run-on sentences, sentence fragments and dangling participles}

According to Kramer et al. (1995), a run-on sentence occurs when more than one independent clause clusters together without proper conjunctions to connect them (in the present study, comma splices were also included in this category); a sentence fragment refers to a string of words wrongly used as an independent clause; and a dangling modifier is defined as a modifier which has nothing to modify because the word it should logically modify is not present in the sentence. The reason for combining these three kinds of errors into one group was that they were all supposed to be errors concerning the completeness of a sentence. $41(6.6 \%)$ such errors were identified in the present study, which can be illustrated by the following three examples.

(14) But be hopeful and optimistic, /there is always something nice waiting for us.

(15) Because as long as Edward was still "alive", he would make a ice sculpture of Kim every winter, showing his love and care.

(16) When mentioning beer, the city of Harbin should not be forgotten as the original place of beer.

Example (14) is a typical run-on sentence found in the student's writing, which required a proper conjunction to connect the two independent clauses in the sentence; (15) is an example of sentence fragments which was a dependent clause starting with because; (16) is an example of dangling participles in that there was actually no subject present in the sentence for the participle mentioning to modify. All these might be because many participants desired "to write more complex sentences in English" (item 16), as reported in the Appendix. When producing complex sentences (item 3), $33 \%$ of the respondents tended to make mistakes.

\subsubsection{Errors in word order}

$31(5 \%)$ errors in word order were coded in the present study, which mainly involved the position of auxiliaries in negative sentences, general questions, wh-questions as well as in dependent clauses and the position of certain adverbs in sentences. Examples are as follows:

(17) But it was because we were too busy?

(18) He also may be late for important appointments.

The correct order for these two examples should be "But was it because ..." and "He may also be ..." respectively. The possible reason for such a mistake might be that the word order in their mother tongue (Chinese) is much more flexible than that in English, as discussed in Cai (2001) and Li (1996).

\subsubsection{Ill parallelism or ill comparison}

In the present study, ill parallelism referred to a parallel structure in which its parallel elements were not grammatically parallel to one another; and ill comparison involved both an illogical comparison, in which the two items being compared were not actually comparable, and an incomplete comparison, in which a necessary part of the comparison was left out, thus causing an ambiguous expression. For example:

(19) ....such as British, Japan, American and so on.

(20) For Gump love is the most important thing, not only the love of his mother, but also Jenny.

In (19), the people of certain nations were supposed to be compared or paralleled with the names of countries: Japan indicated a country, while British and American referred to people. In (20), the two parts immediately after not only and but also were different in terms of both grammatical structure and semantic meaning.

\subsubsection{Mixed or confused sentences}

$57(9.2 \%)$ errors of mixed or confused sentences were identified in the present study, which referred to a faulty construction resulting from two or more structures being mixed together without a clear recognition of either of them. The following are some examples.

(21) Secondly, he tells about the real memories of childhood impact his style of fictions.

(22) Soon we knew each other and became good friends and which even means brothers or sisters.

In example (21), the writer seemed to say that he tells about his early childhood memories which had a great impact on his fiction style, but ending up with a mixture of the main clause and the attributive clause with the omission of the necessary subordinating conjunction which. In example (22), the writer complicated his or her sentence by adding an unnecessary attributive clause when indicating the degree of the intimacy, like brothers or sisters, while the writer could have simply said that soon we knew each other and became good friends, and in the end, we were like brothers and sisters.

\subsubsection{Patterns of the errors in individual tasks}

The number and percentage of each category of syntactic errors in each individual task were presented in Table 2. For all the three tasks, $\mathrm{Sb}$ (errors in tense, voice \& auxiliaries) were the most frequently made errors, consistent with that of the whole sample. Then a mixed pattern was observed about the distribution of the errors for the tasks: $\mathrm{Si}$ (errors in the 
use of articles) constituted the second most frequently occurring type of errors in task A, followed by Sh (mixed structure), Se (run-on, fragment \& dangling participle), and Sd (agreement errors). In task C, Sc (conjunction errors) was the second most frequently made type of errors, followed by Si, Sa (errors in part of speech) and Sd. And in task D, the second most often made error type was Sc followed by Sa, and Sd. This suggests that how to properly use tense and voice of a verb and auxiliary verb was the biggest challenge for the participants of the present study. They also had much difficulty in appropriately using articles, conjunctions, part of speech and producing grammatically correct mixed sentences, long sentences and sentences with dangling participles.

Table 2. Syntactic Errors in Individual Tasks

\begin{tabular}{cccc}
\hline Type of errors & Task A & Task C & Task D \\
\hline $\mathrm{Sa}$ & $18 / 8.8 \%$ & $23 / 9.4 \%$ & $15 / 8.7 \%$ \\
\hline $\mathrm{Sb}$ & $43 / 21 \%$ & $44 / 18 \%$ & $69 / 39.9 \%$ \\
\hline $\mathrm{Sc}$ & $17 / 8.3 \%$ & $37 / 15.2 \%$ & $21 / 12.1 \%$ \\
\hline $\mathrm{Sd}$ & $19 / 9.3 \%$ & $47 / 9.3 \%$ & $15 / 8.7 \%$ \\
\hline $\mathrm{Se}$ & $21 / 10.2 \%$ & $9 / 3.7 \%$ & $11 / 6.4 \%$ \\
\hline $\mathrm{Sf}$ & $15 / 7.3 \%$ & $10 / 4.1 \%$ & $6 / 3.5 \%$ \\
\hline $\mathrm{Sg}$ & $11 / 5.4 \%$ & $5 / 2 \%$ & $7 / 4 \%$ \\
\hline $\mathrm{Sh}$ & $24 / 11.7 \%$ & $21 / 8.6 \%$ & $12 / 6.9 \%$ \\
\hline $\mathrm{Si}$ & $29 / 14.1 \%$ & $36 / 14.8 \%$ & $7 / 4 \%$ \\
\hline $\mathrm{Sj}$ & $8 / 3.9 \%$ & $12 / 4.9 \%$ & $10 / 5.8 \%$ \\
\hline Total: & & $244 / 100 \%$ & $173 / 100 \%$ \\
\hline
\end{tabular}

\subsection{Developmental patterns of the errors across tasks}

A cross-comparison of the total numbers of the errors presented in Table 2 shows that, of the three tasks, task A had the largest number of such errors as Se (run-on sentence, sentence fragment, dangling participle), Sf (errors in word order), $\mathrm{Sg}$ (ill parallelism or ill comparison), and Sh (mixed or confused structure), task $\mathrm{C}$ resulted in the largest number of such errors as $\mathrm{Sa}, \mathrm{Sc}$ (conjunction errors), $\mathrm{Sd}, \mathrm{Si}$, and $\mathrm{Sj}$ (errors concerning single-plural noun form), and task $\mathrm{D}$ yielded the largest number of errors in $\mathrm{Sb}$ (errors in tense and voice).

Table 2 also shows that the overall number of syntactic errors increased to 244 in task C from 205 in task A and then decreased to 173 in task D. A similar pattern was noted for specific types of syntactic errors: $\mathrm{Sa}, \mathrm{Sc}, \mathrm{Si}$, and $\mathrm{Sj}$. The participants seemed to commit more errors of different categories in task $\mathrm{C}$ but fewer errors in task D. This might be because task $\mathrm{C}$ which required the students to write a critical review of an article or book was more challenging than the other two tasks which were more familiar to them.

Meanwhile, the paired samples t-test results reported in Table 3 demonstrate that not all the differences were statistically significant.

Table 3. Results of Paired Samples t-tests

\begin{tabular}{ccccccc}
\hline \multirow{2}{*}{ Type of errors } & \multicolumn{2}{c}{ Tasks A vs C } & \multicolumn{2}{c}{ Tasks A vs D } & \multicolumn{2}{c}{ Tasks C vs D } \\
\cline { 2 - 7 } & $\mathrm{T}$ & $\mathrm{P}$ & $\mathrm{t}$ & $\mathrm{p}$ & $\mathrm{t}$ & $\mathrm{P}$ \\
\hline $\mathrm{Sa}$ & .656 & .517 & -.379 & .708 & -.955 & .348 \\
\hline $\mathrm{Sb}$ & .082 & .939 & $\mathbf{2 . 6 3}$ & .026 & $\mathbf{2 . 4 7}$ & .046 \\
\hline $\mathrm{Sc}$ & $\mathbf{2 . 6 2}$ & .041 & .538 & .595 & -1.490 & .147 \\
\hline $\mathrm{Sd}$ & $\mathbf{2 . 6 8}$ & .038 & -.571 & .573 & $\mathbf{- 3 . 7 9}$ & .000 \\
\hline $\mathrm{Se}$ & -1.33 & .194 & -1.16 & .257 & .287 & .702 \\
\hline $\mathrm{Sf}$ & -1.15 & .258 & -1.87 & .071 & -.372 & .293 \\
\hline $\mathrm{Sg}$ & -1.53 & .136 & -.89 & .380 & .326 & .536 \\
\hline $\mathrm{Sh}$ & -.593 & .557 & -1.84 & .068 & -1.34 & .056 \\
\hline $\mathrm{Si}$ & .793 & .434 & $\mathbf{- 3 . 7 2}$ & .001 & $\mathbf{- 2 . 8 9}$ & .001 \\
\hline $\mathrm{Sj}$ & .812 & .423 & .528 & .601 & -.287 & .702 \\
\hline $\mathrm{Total}$ & 1.65 & .197 & -1.87 & .201 & $\mathbf{- 2 . 9 7}$ & .003 \\
\hline
\end{tabular}

As noted from Table 3, significant difference occurred in Sc (conjunction errors) $(\mathrm{t}=2.62, \mathrm{p}=.041)$ and Sd (agreement errors) $(\mathrm{t}=2.68, \mathrm{p}=.038)$ between tasks $\mathrm{A}$ and $\mathrm{C}$, in $\mathrm{Sb}$ (errors in tense, voice \& auxiliaries) $(\mathrm{t}=2.63, \mathrm{p}=.026)$ and $\mathrm{Si}$ (use of articles) $(\mathrm{t}=-3.72, \mathrm{p}=.001)$ between tasks $\mathrm{A}$ and $\mathrm{D}$, and in $\mathrm{Sb}(\mathrm{t}=2.47, \mathrm{p}=.046), \mathrm{Sd}(\mathrm{t}=-3.79, \mathrm{p}=.00 \mathrm{o}), \mathrm{Si}(\mathrm{t}$ $=-2.89, \mathrm{p}=.001)$, and overall syntactic errors $(\mathrm{t}=-2.97, \mathrm{t}=.003)$ between tasks $\mathrm{C}$ and $\mathrm{D}$. Namely, compared with task $\mathrm{A}$, the participants produced significantly more conjunction and agreement errors in task $\mathrm{C}$, significantly more errors in tense, voice and auxiliary verbs in task D, and significantly less errors of the use of articles in task D. Compared with 
task $\mathrm{C}$, the respondents made significantly more errors in tense, voice and auxiliary verbs in task D, but significantly less errors of agreement and the use of articles, and overall syntactic errors in task D. This might be still because of the difficulty of and the students' familiarity with the tasks. Meanwhile, it suggests that the students became more capable of using agreement and articles more appropriately in their English writing after eight weeks' training and practice. Their overall ability to write grammatically correct English sentences was enhanced as well. However, the number of errors in tense, voice and auxiliary verbs $(\mathrm{Sb})$ continued to increase across the three tasks, implying that this type of errors still remained a big challenge to the students. Likewise, the numbers of errors concerning run-on sentences, fragments and dangling participle (Se), and ill parallelism or ill comparison $(\mathrm{Sg})$ increased in task D compared with those in task B, indicating they still constituted a (big) obstacle to the students as well. Namely, these persistent errors need special attention during the teaching and learning of English writing.

\subsection{Correlations between errors and students' writing performance}

To explore how the syntactic errors were related to the students' writing performance, correlation analyses were conducted. The results are reported in Table 4.

Table 4. Correlations between the Syntactic Errors and Writing Performance

\begin{tabular}{|c|c|c|c|c|c|c|c|c|c|c|c|}
\hline & $\mathrm{Sa}$ & $\mathrm{Sb}$ & Sc & $\mathrm{Sd}$ & $\mathrm{Se}$ & Sf & $\mathrm{Sg}$ & Sh & $\mathrm{Si}$ & $\mathrm{Sj}$ & Total \\
\hline A & -.23 & $-.40 *$ & -.33 & $-.52 * *$ & $-.37 *$ & .01 & -.25 & $-.40 *$ & -.32 & .08 & -.23 \\
\hline $\mathrm{C}$ & -.21 & .05 & $-.40 *$ & .04 & .25 & $-.39 *$ & -.04 & -.26 & -.26 & -.32 & $-.42 *$ \\
\hline D & .11 & .17 & $-.41 *$ & -.09 & -.23 & .05 & -.10 & -.21 & .15 & -.21 & -.21 \\
\hline
\end{tabular}

$\mathrm{A}, \mathrm{C}, \mathrm{D}=$ students' scores in writing tasks $\mathrm{A}, \mathrm{C}$ and $\mathrm{D}$ respectively

As shown in Table 4, all types of errors except $\mathrm{Sf}$ and $\mathrm{Sj}$ were inversely correlated with the students' scores in task A, all except Sb, Sd, and Se were negatively related to the scores in task C, and so were all except $\mathrm{Sa}, \mathrm{Sb}, \mathrm{Sf}$, and $\mathrm{Si}$ to the scores in task D. Among these correlations, $\mathrm{Sb}(r=-.40), \mathrm{Sd}(r=-.52)$, $\mathrm{Se}(r=-.37)$, and $\mathrm{Sh}(r=-.4)$ were significantly negatively correlated with scores in task A; Sc $(r=-.40)$, Sf $(r=-.39)$ and overall syntactic errors $(r=-.42)$ were significantly inversely related to scores in task C; and so was Sc $(r=-.41)$ to the scores in task D. Namely, Sb, Sc, Sd, $\mathrm{Se}, \mathrm{Sf}$, and Sh were significantly correlated with the students' performance in writing: the more these types of errors were, the worse the students performed in a writing task.

\subsection{Causes for the errors}

Analyses of the data revealed that around or more than $40 \%$ of the respondents believed that their grammatical errors were the result of insufficient grammatical knowledge (item 10), carelessness (item 11), the lack of writing practice (item 13), or the desire to write more complex sentences in their writing (item 16). Around a third of them attributed the errors to the lack of proofreading (item 12), and the influence of Chinese (items 14-15). This was further supported by their responses to the open-ended questions, which revealed that 12 of 30 (question 18) respondents reported carelessness (or too careless or not careful enough) to be the main cause for their grammatical errors, while 16 attributed their syntactic errors to the lack of sufficient English writing practice, and insufficient grammatical knowledge due to a long time's separation from grammar study since the high school.

As reported in the Appendix, 47\% of the respondents (strongly) agreed with item 11 that they made grammatical mistakes in their English writing due to carelessness, and 61\% (strongly) vetoed item 15 that grammatical mistakes in their English writing could be traced back to the influence of Chinese. These results clearly indicate that the students were confident about the grammatical rules in English and were (quite) aware of the differences between Chinese and English; However, they lackedcarefulness, which often resulted in the errors in their writing. This was further supported by their responses to the open-ended questions which reported that carelessness was a principal reason for several types of errors: part of speech, use of conjunctions, use of articles, and use of single or plural forms of nouns in their writing.

Differences between Chinese and English, though not so strongly held by the students (items 14-15), can actually explain lots of the errors (e.g., part of speech, passive voice, the use of compound and complex sentences, agreement, word order, use of single or plural forms of nouns, etc.) they committed in their writing (Cai, 2001; He, 2002; Li, 1996; Lian, 1993). For example, though Chinese and English share a similar way of categorizing words into nouns, adjectives, verbs, adverbs and so on, many Chinese words, especially adjectives and verbs, are more flexible in terms of their functions in a sentence than their counterparts in English (He, 2002). Meanwhile, Chinese words do not take inflectional or derivational changes in the way English words do (Li, 1996). For instance, the Chinese word 'piao liang' (pretty or beautiful) is mainly considered an adjective in Chinese; however, it can serve different functions in different sentences. Consequently, Chinese students often forget to change the word form to match its function in a sentence and also tend to use one word to perform diverse functions in their English writing.

In addition to these two main reasons, other causes such as unfamiliarity with the grammatical rules, the desire to write more complex sentences in their writing, and lack of proofreading might have worked together to lead to the errors of various types in the students' real writing products in the present study. 


\section{Conclusions and implications}

The present study identified 622 syntactic errors at the sentence level existing in 90 English essays composed by 30 undergraduate non-English majors on three tasks spanning eight weeks. Analyses of these errors across tasks yielded the following conclusions.

Among the ten types of syntactic errors, errors in tense and voice ( $\mathrm{Sb}$ ) accounted for the largest percentage of the whole sample, followed by agreement errors $(\mathrm{Sd})$, conjunction errors $(\mathrm{Sc})$, and the use of articles ( $\mathrm{Si}$ ). Errors of these categories also occurred most frequently in each individual task. Comparison of the number of the errors across tasks revealed that the overall syntactic errors, as well as the specific types of syntactic errors, generally tended to decrease in the last two tasks. Paired samples t-tests results showed that the participants made significantly more errors in tense, voice and auxiliary verbs, but significantly less errors in the use of articles and agreement in the last task. Meanwhile, correlation analyses suggested that the syntactic errors of various categories were generally negatively related to the students' writing performance, of which the correlations between $\mathrm{Sb}, \mathrm{Sd}, \mathrm{Sc}, \mathrm{Se}, \mathrm{Sf}$, Sh and the latter were statistically significant. And some causes for the errors were identified by the participants, among which carelessness and the differences between Chinese and English were considered to be the most crucial.

These findings imply that the eight weeks' training and practice enabled the students to produce significantly less grammatically correct sentences in their English writing. Thus, training and practice proved to be beneficial to improve the quality of the students' English writing. However, the findings also suggest that how to properly use the tense and voice of a verb and auxiliary verbs remained the biggest challenge for the participants of the present study, followed by how to appropriately use articles, conjunctions, part of speech, and how to produce grammatically correct mixed sentences, long sentences and sentences with dangling participles. Hence, grammar should continue to remain a focus during the teaching and learning of English writing. Given that some syntactic errors, like errors in tense and voice and agreement errors were made quite frequently yet unconsciously by some students in their writing, it would be helpful for the teachers to design some essay revising exercises for them to increase their awareness of such errors and urge them to become more careful when producing English sentences. Furthermore, since the influence of Chinese was considered a principal cause for many types of syntactic errors in the present study, an explicit explanation and understanding of the differences between Chinese and English may prove to be effective for Chinese EFL learners to finally overcome the negative influence of their mother tongue. An appropriate use of translation from Chinese to English or vice versa may help to achieve this aim.

\section{Limitations and suggestions for future research}

Due to various constraints, several limitations exist in the present study. First of all, if the sample used in the study were larger, the findings would have been more generalizable. Secondly, if the three tasks were of the same genre and the period of the study had lasted longer, it would have revealed a clearer developmental pattern of each type of errors. Moreover, due to limited space, paragraph- and text-level errors were not covered in the present study. Otherwise, a more comprehensive picture would have been depicted for the written errors existing in the undergraduate students' English writing. For this reason, it is suggested that studies with a larger sample, a longer studying period and more error types should be conducted in the future.

Finally, as revealed in the present study, the participants were aware that they were likely to make certain types of errors such as the use of tense, voice, and modality. Meanwhile, they might be ignorant of the probability of making other types of errors such as errors in agreement and single/plural forms of nouns, although they claimed they were capable of using them appropriately. To better understand this, it is necessary to analyze more students' writing and compare their actual work with their perceptions. When necessary, stimulated recall can be helpful to elicit more ideas from the students.

\section{References}

Bardovi-Harlig, K., \& Bofman, T. (1989). Attainment of syntactic and morphological accuracy by advanced language learners. Studies in Second Language Acquisition, 11, 17-34.

Cai, J. (2001). A comparative study of English writing. Shanghai: Fudan University Press.

Chan, A. Y. W. (2004). Syntactic Transfer: Evidence from the Interlanguage of Hong Kong Chinese ESL Learners. The Modern Language Journal, 88, 56-74.

Cheng, J. (1994). On the teaching of English writing. Foreign Language Teaching and Research, 98, 12-18

Corder, S. P. (1967). The significance of learners’ errors. International Review of Applied Linguistics, 5, 161-169.

Crompton, P. (2005). "Where", "In which", and "in that": a corpus-based approach to error analysis. RELC Journal, 36, 157-176.

Crusan, D. (2002). An assessment of ESL writing placement assessment. Assessing Writing, 8, 17-30.

Dam, P. (2001). Old habits die hard: persistent errors in English written by Vietnamese speakers [Online]. Available: http://www.quangio.com/quangio/damtrungphap1101.htm (March 10, 2011). 
Du, Y. (2004). An investigation of the errors in spoken English produced by university freshmen. Foreign Language Teaching and Research, 103, 94-97.

Feng, C., Ogata, H., \& Yano, Y. (2000). Mark-up-based writing error analysis model in an on-line classroom. Computer Assisted Language Learning, 13, 79-97.

Ferris, D., \& Roberts, B. (2001). Error feedback in L2 writing classes: how explicit does it need to be? Journal of Second Language Writing, 10, 161-184.

Frantzen, D. (1995). The effects of grammar supplementation on written accuracy in an intermediate Spanish content course. Modern Language Journal, 79, 329-344.

French, G. (2005). The cline of errors in the writing of Japanese university students. World Englishes, 24, 371-382.

He, S. (2002). A comparative study of English and Chinese languages. Shanghai: Shanghai Foreign Language Education Press.

Hinkel, E. (2001). Matters of cohesion in L2 academic texts. Applied Language Learning, 12, 111-132.

Hsin, A. C. (2003). Indefinite subject NPs between English and Chinese: an error analysis [Online]. Available: http://www.cal.org/ericcll/releaseform.html (March 15, 2011).

Huang, L. S. (2001). Knowledge of English collocations: an analysis of Taiwanese EFL learners. Texas papers in Foreign Language Education: Selected Proceedings from the Texas Foreign language education Conference, 6, 256264.

Hyland, K., \& Anan, E. (2006). Teachers' perceptions of error: The effects of first language and experience. System, 34, 509-519

James, C. (1998). Errors in language learning and use. Addison Wesley: Longman Inc.

Khuwaileh, A. A., \& Shoumali, A. A. (2000). Writing errors: a study of the writing ability of Arab learners of academic English and Arabic at university. Language, Culture, and Curriculum, 13, 174-183.

Kim, S. A. (2001). Characteristics of EFL readers' summary writing: A study with Korean university students. Foreign Language Annals, 34, 569-581.

Kramer, M. G., Leggett, G., \& Mead, D. (1995). Prentice Hall Handbook for Writers. Englewood Cliffs, NJ: Prentice Hall.

Li, R. (1996). A comparative study of English and Chinese languages and cultures. Shanghai: Shanghai Education Press.

Lian, S. (1993). A comparative study of English and Chinese. Beijing: Higher Education Press.

Liu, C., \& Yang, S. (2006). A study on the misuse of words among Chinese EFL learners. Foreign Language World, 8, 301-304.

Liu, M., \& Braine, G. (2005). Cohesive features in argumentative writing produced by Chinese undergraduates. System, 33, 623-636.

Liu, M., \& Chai, Y. (2009). Attitudes towards peer review and reaction to peer feedback in Chinese EFL writing classrooms. TESL Reporter, 40, 33-50.

National Educational Examinations Authority and National College English Test Committee [Online]. (2009). Available: http://www.edu.cn/20051222/3167199.shtml (Dec. 21, 2012).

Polio, C. G. (1997). Measures of linguistic accuracy in second language writing research. Language Learning, 47, 101143

$\mathrm{Su}$, H. (2002). Error analysis of the transitional verbs produced by Chinese EFL learners. Foreign Language Teaching, 23, 36-41.

Tang, L. (2000). Error analysis on the written expressions produced by Chinese EFL Learners. Foreign Languages and their Teaching, 12, 56-61.

Taylor, G. (1986). Errors and explanations. Applied Linguistics, 7, 144-166.

Wang, D. (2003). The impact of English and Chinese thinking styles on their languages. Foreign Languages and their Teaching, 3, 33-40.

Wang, J. (2005). From ideas to text: A cognitive study of English writing processes. Jinan: Shandong University Press.

Zhang, W. (2004). The rhetorical patterns found in Chinese EFL student writers' examination essays in English and the influence of these patterns on rater response. Beijing: Tsinghua University Press.

Zhang, Z., Wu, H., Wang, X., \& Zhang, J. (1995). Main problems about the teaching of English writing in China. Foreign Language Teaching and Research, 104, 43-50. 


\section{Appendix: Perceptions of the difficulties and syntactic errors in English writing}

Directions: This survey aims to explore students' perceptions of the difficulties and syntactic errors in their English writing. Please read the statements carefully and choose an alternative for each statement that suits you best from the five choices: $\mathrm{SD}=$ Strongly disagree; $\mathrm{D}=$ Disagree; $\mathrm{N}=$ Not sure; $\mathrm{A}=$ Agree; $\mathrm{SA}=$ Strongly agree. All the data collected herewith will be used for research only.

Name:

Gender:

Age:

\begin{tabular}{|c|c|c|c|c|c|}
\hline & SD & $\mathrm{D}$ & $\mathrm{N}$ & A & SA \\
\hline $\begin{array}{l}\text { 1. 我觉得写出语法正确的句子很难 (I think it very difficult to } \\
\text { write grammatically correct sentences). }\end{array}$ & $27 \%$ & $37 \%$ & $23 \%$ & $13 \%$ & $0 \%$ \\
\hline 2. 我经常犯时态错误 (I often make mistakes in tense and voice). & $7 \%$ & $43 \%$ & $10 \%$ & $30 \%$ & $10 \%$ \\
\hline $\begin{array}{l}\text { 3. 我在写复杂句时常出错 (I often make mistakes when producing } \\
\text { complex sentences)。 }\end{array}$ & $17 \%$ & $37 \%$ & $13 \%$ & $30 \%$ & $3 \%$ \\
\hline 4. 我经常弄混词性 (I often make mistakes in part of speech). & $17 \%$ & $50 \%$ & $20 \%$ & $10 \%$ & $3 \%$ \\
\hline 5. 我常犯冠词错误 (I often make mistakes with articles). & $13 \%$ & $67 \%$ & $7 \%$ & $13 \%$ & $0 \%$ \\
\hline 6. 我对连接词的使用不好 (I'm not good at using conjunctions). & $17 \%$ & $27 \%$ & $19 \%$ & $21 \%$ & $16 \%$ \\
\hline $\begin{array}{l}\text { 7. 我在主谓一致方面没问题 (I have no problem with subject- } \\
\text { predicate agreement). }\end{array}$ & $18 \%$ & $21 \%$ & $16 \%$ & $29 \%$ & $16 \%$ \\
\hline $\begin{array}{l}\text { 8. 我在指代一致方面没问题 (I have no problem with pronoun- } \\
\text { antecedent agreement). }\end{array}$ & $15 \%$ & $25 \%$ & $13 \%$ & $28 \%$ & $19 \%$ \\
\hline $\begin{array}{l}\text { 9. 我能准确使用英语名词的单复数 (I can accurately use the } \\
\text { singular or plural form of nouns in English). }\end{array}$ & $13 \%$ & $17 \%$ & $10 \%$ & $33 \%$ & $27 \%$ \\
\hline $\begin{array}{l}\text { 10. 我犯语法错误是因为语法知识不扎实 (I make grammatical } \\
\text { mistakes because of insufficient grammatical knowledge). }\end{array}$ & $10 \%$ & $27 \%$ & $23 \%$ & $33 \%$ & $7 \%$ \\
\hline $\begin{array}{l}\text { 11. 我犯语法错误是因为马虎 (I make grammatical mistakes } \\
\text { because of carelessness). }\end{array}$ & $3 \%$ & $17 \%$ & $33 \%$ & $37 \%$ & $10 \%$ \\
\hline $\begin{array}{l}\text { 12. 因为很少检查, 我英语作文中的语法错误较多 (There are } \\
\text { many grammatical mistakes in my writing because I seldom } \\
\text { proofread it). }\end{array}$ & $14 \%$ & $40 \%$ & $20 \%$ & $23 \%$ & $3 \%$ \\
\hline $\begin{array}{l}\text { 13. 我犯语法错误是因为缺乏写作练习 (I make grammatical } \\
\text { mistakes due to the lack of writing practice). }\end{array}$ & $6 \%$ & $17 \%$ & $17 \%$ & $60 \%$ & $0 \%$ \\
\hline $\begin{array}{l}\text { 14. 我犯句法结构错误是因为受汉语语句的影响 (I make } \\
\text { mistakes in sentence structure because of the influence of Chinese). }\end{array}$ & $6 \%$ & $30 \%$ & $27 \%$ & $27 \%$ & $10 \%$ \\
\hline $\begin{array}{l}\text { 15. 我犯语法错误是因为受汉语的影响 (I believe the } \\
\text { grammatical mistakes in my English writing are due to the } \\
\text { influence of Chinese). }\end{array}$ & $14 \%$ & $47 \%$ & $17 \%$ & $17 \%$ & $7 \%$ \\
\hline $\begin{array}{l}\text { 16. 我犯语法错误是因为想多用复杂句, 为了让自己的文章显 } \\
\text { 得有水平 }\end{array}$ & $17 \%$ & $23 \%$ & $23 \%$ & $37 \%$ & $0 \%$ \\
\hline $\begin{array}{l}\text { (I make grammatical mistakes because I desire to write more } \\
\text { complex sentences in English). }\end{array}$ & & & & & \\
\hline
\end{tabular}

17.我常犯的语法错误是 (I often make such grammatical mistakes as)

18. 我常犯语法错误是因为 (I often make grammatical mistake because) 